\title{
Removal of Optimal Cutting Temperature (O.C.T.) Compound from Embedded Tissue for MALDI Imaging of Lipids.
}

\author{
Authors: Jacob XM Truong ${ }^{1,2}$, Xander Spotbeen ${ }^{1,3}$, Jake White ${ }^{1,2}$, Johannes V Swinnen ${ }^{3}$, Lisa M Butler ${ }^{1,2}$, Marten \\ F Snel $^{1}$, Paul J Trim ${ }^{1}$.
}

\begin{abstract}
Matrix-assisted laser desorption/ionisation mass spectrometry imaging (MALDI-MSI) is a common molecular imaging modality used to characterise the abundance and spatial distribution of lipids in situ. There are several technical challenges predominantly involving sample pre-treatment and preparation. Two technical issues which have complicated the analysis of clinical tissues by MALDI MSI are the common embedding of samples in Optimal Cutting Temperature (O.C.T.), which contain high concentrations of polyethylene glycol (PEG). These polymers cause analyte signal suppression during mass spectrometry (MS) by competing for available ions during ionisation, which has constrained the application of MALDI-MSI for clinical tissues. Another challenge is the complexity of the mass spectra obtained. The process of analyte ion formation during MALDI can generate multiple adducts from a single molecular species due to the presence of alkali salts in tissues, resulting in multiple $\mathrm{m} / \mathrm{z}$ peaks corresponding to individual lipids, suppression of protonated adduct formation and the generation of multiple near isobaric ions. Presented is a method to simultaneously remove O.C.T. and endogenous salts, applicable to MALDI MSI of lipids preventing analyte suppression, whilst simplifying data interpretation and improve sensitivity by promoting lipid protonation and reducing the formation of alkali adducts.
\end{abstract}

Paul J Trim

paul.trim@sahmri.com

1 South Australian Health and Medical Research Institute (SAHMRI)

North Terrace, Adelaide 5000

South Australia, Australia.

2 The University of Adelaide Medical School and Freemasons Foundation Centre for Men's Health,

North Terrace, Adelaide 5005

South Australia, Australia.

3 Laboratory of Lipid Metabolism and Cancer, LKI Leuven Cancer Institute, KU Leuven, B-3000 Leuven, Belgium
Jacob XM Truong - ORCID 0000-0002-4930-7076

Xander Spotbeen - ORCID 0000-0002-1510-967X

Jake White - ORCID 0000-0003-3903-8703

Johannes V Swinnen - ORCID 0000-0002-7720-5077

Lisa M. Butler- ORCID 0000-0003-2698-3220

Marten F Snel - ORCID 0000-0002-8502-7274

Paul J. Trim - ORCID 0000-0001-8734-3433

Keywords:

MALDI MSI, O.C.T., Ammonium Formate, Lipid Imaging

Introduction:

Matrix-assisted laser desorption ionisation (MALDI) mass spectrometry imaging (MSI) is an invaluable method for direct tissue analysis that measures and visualises the relative abundance and spatial distribution of different biomolecules including peptides (Angel, Norris-Caneda \& Drake 2018; Beine et al. 2016; Chatterji et al. 2014), drugs (Mutuku et al. 2019; Ntshangase et al. 2019; Schulz et al. 2019), lipids (Berry et al. 2011; Gode \& Volmer 2013; Goto et al. 2015; Meisenbichler et al. 2019; Randall et al. 2019), nucleotides (Nakashima \& Setou 2018; Yokoi et al. 2018) and other cellular metabolites (Ucal et al. 2017). It is increasingly being adopted as an analytical technique by researchers characterising the fundamental molecular changes that occur in pathologies of disease, both infectious (Blanc et al. 2018; Kadesch et al. 2019; Santos et al. 2018) and non-infectious (Kurreck et al. 2018). Unlike protein imaging, where the spatial distribution and relative abundance of proteins can be detected through robust techniques such as immunohistochemistry (IHC), there are considerably fewer label-free techniques for the in situ analysis of lipids, especially when detail on headgroup and acyl chain composition are required. Recently however, many studies have shown the usefulness of MALDI MSI in spatial lipidomic analyses, mapping and identifying several species of lipids in human (Goto et al. 2014; Randall et al. 2019; Veloso et al. 2011) and animal models (Flinders et al. 2018; Mallah et al. 2018). Recently MALDI MSI has been extensively applied in 
cancer research as a potential diagnostic and biomarker discovery tool (Goto et al. 2015; Goto et al. 2014; Randall et al. 2019; Schwamborn 2012; Ucal et al. 2017). Furthermore, unlike molecular imaging techniques such as IHC, MALDI MSI can detect hundreds of analytes simultaneously, with little to no pre-requisite knowledge for target molecules, making it a useful tool for discovery studies.

Sample preparation is a core component of the analysis of lipids by MALDI MSI. While typically more time consuming than sample preparation for other MSI techniques such as desorption electrospray ionisation (DESI) and secondary ion mass spectrometry (SIMS), sample preparation is still time efficient with respect to traditional MS workflows, which often require long incubation periods for analyte retrieval and purification or protein digestion (Longuespee et al. 2016). Optimisation of this process is fundamental to maximising resolution and sensitivity of analyte detection. Sample preparation for MALDI MSI includes tissue collection, optional embedding in a medium, cryosectioning and application of a suitable matrix (Gode \& Volmer 2013; Goto-Inoue et al. 2011) commonly by sublimation (Goto et al. 2014) or automated spray coating (Mounfield \& Garrett 2012). Washing tissues with a solution containing organic salts prior to matrix application can be added as a beneficial step for imaging. It has been shown to significantly improve the number of detected analytes with seven-fold increases in signal intensity for specific lipid species in negative ion mode MALDI (Angel et al. 2012). This effect is due to the removal of endogenous salts found in the tissues, which prevents the formation of cation adducts (Meisenbichler et al. 2019). Furthermore, freezing tissues in an embedding medium is common practice to preserve samples for future analysis that requires cryosectioning. This helps to maintain tissue integrity during freezing and long storage, and assists in cryosectioning by providing a stable and smooth cutting surface (Schwartz, Reyzer \& Caprioli 2003) that does not interfere with common tissue staining procedures. However, tissue embedding can be problematic for MS analysis. Most frozen tissue samples used for biomedical research are collected and embedded in O.C.T. (Optimal Cutting Temperature) compound. O.C.T. has been known to cause ion suppression and decrease spectrum quality from MS experiments (Schwartz, Reyzer \& Caprioli 2003). This suppression effect observed in O.C.T. embedded tissue is believed to be the result of contamination by polyethylene glycol (PEG), one of the main ingredients, competing with analyte molecules for the available ions during the ionisation stage, in addition salts present in the compound can lead to the formation of unwanted adduct ions (Berry et al. 2011). The result of these processes is a mass spectrum that contains limited analyte signal and a pattern of dominant peaks separated by $44 \mathrm{Da}$ intervals, the $-\mathrm{CH}_{2}-\mathrm{CH}_{2}-\mathrm{O}$ - repeatunit of the PEG polymer (Weston \& Hummon 2013). This presents a significant problem for researchers in areas such as cancer where a significant proportion of biopsies stored in biobanks are O.C.T. embedded. To circumvent this, alternative "MS-friendly" embedding media such as carboxymethylcellulose (CMC) (Bhandari et al. 2014) (Enthaler et al. 2012) poly[N-(2hydroxypropyl)] methacrylamide (Strohalm et al. 2011) and gelatin (Andersen et al. 2020; Gill et al. 2017) have been used when MS analysis is intended. These media are beneficial by not inhibiting analyte ionisation whilst remaining histologically compatible. Embedding alternatives provide little assistance to researchers whose samples have already been embedded in O.C.T., and whose access to alternatives are limited. To address this, some (Rohrbach et al. 2020; Shah et al. 2015; Tian, Bova \& Zhang 2011; Weston \& Hummon 2013; Zhang, W et al. 2015) have attempted to remove O.C.T. from embedded samples to improve compatibility with MS and restore maximum analyte ion yield. Addressing the O.C.T. question is becoming a greater priority, as MS becomes a routinely used technique for biomedical research. For example, one group has demonstrated a 'Chemical Immobilisation of Proteins for Peptide Extraction (CIPPE)' procedure which entailed reductive amination of proteins in an O.C.T. embedded sample to a beaded column (Shah et al. 2015) Additionally, Weston and Hummon compared the effectiveness of three methods; Short SDS-PAGE, filter aided sample preparation (FASP) and ether-methanol precipitation, that could be applied to remove O.C.T., all of which were reported to sufficiently remove the contaminant and restore quality analyte signal by LC-MS/MS (Weston \& Hummon 2013). While these findings establish that removal of O.C.T. is indeed possible for isolating peptides for MS analysis with minimal loss, they seemingly require the use of extensive tissue treatment with various chemicals, these procedures cannot be adapted for the in situ analysis of lipids by MALDI MSI as preservation of tissue structure and localisation of analytes is fundamental to drawing meaningful results and conclusions from the data. Therefore, a procedure is required that can efficiently remove O.C.T. from embedded tissue whilst minimizing the loss of spatial information.

Here we present a comprehensive tissue preparation procedure that facilitates the removal of O.C.T. from embedded tissues that is compatible with MALDI MSI workflows for lipid imaging (Figure 1). Furthermore, we demonstrate that this dual-purpose wash can also improve the detection and spatial localisation of protonated lipid species through removal/dilution of alkali metal ions.

\section{Materials and Methods:}

Tissue-Tek O.C.T. compound was purchased from Thermo Scientific. MALDI matrix 2,5dihydroxybenzoic acid (DHB) $(95 \%)$ was purchased from Sigma Aldrich. ITO conductive IntelliSlides were 
provided by Bruker Daltonik. 150mM Ammonium Formate was prepared from a dry powder purchased from Honeywell. Tune Mix was purchased from Agilent Technologies. TA30 solvent (70:30 Acetonitrile: 0.1\% trifluoroacetic acid (TFA) was prepared using TFA (Sigma Aldrich) and acetonitrile (Honeywell). Lipid standards were purchased from Avanti Polar Lipids (AL, USA)

\section{Human Tissue Samples:}

Prostate cancer tissue embedded in O.C.T. was obtained from the Australian Prostate Cancer BioResource (Adelaide, Australia). Ethical approval for the use of human prostate tumours was obtained from the Ethics Committees of the University of Adelaide (Adelaide, Australia) and St Andrew's Hospital (Adelaide, Australia). All biobanking procedures and patient consenting were performed in accordance with the guidelines of the National Health and Medical Research Council (Australia).

\section{$\underline{\text { Human Tumour Xenograft Samples: }}$}

After sacrifice, prostate xenograft tissues removed from mice were harvested, bisected and half immediately embedded in O.C.T. followed by both halves being snap frozen in liquid nitrogen. Xenograft tissues were stored at $-80^{\circ} \mathrm{C}$ until analysis. The tissues were obtained as surplus from a study approved by the Animals Ethics Committee of the University of Adelaide (Australia).

\section{Sectioning:}

Sections were cut on a Shandon Cryotome E (Thermo Scientific, MA, USA) at $-18^{\circ} \mathrm{C}$. Samples were removed from $-80^{\circ} \mathrm{C}$ storage and warmed to $-18^{\circ} \mathrm{C}$ for 30 minutes prior to sectioning. Four sections per human prostate sample were cut to $10 \mu \mathrm{m}$ thickness and thaw-mounted onto ITO conductive intellislides (Bruker, Bremen, Germany). Two patients' tissues were analysed per slide for a total of 8 sections each slide. Xenograft prostate samples were sectioned at the same temperature and thickness. Four sections were cut from both O.C.T. embedded and non-embedded samples and mounted onto separate ITO slides. 1 serial section per patient/xenograft tissue was cut and thaw mounted on a Superfrost Plus glass slide (Thermo Scientific, MA, USA) for Haematoxylin and Eosin (H\&E) staining.

\section{Washing:}

For maximum removal of O.C.T. and endogenous $\mathrm{Na}^{+}$ and $\mathrm{K}^{+}$, tissues were washed using a method adapted from Angel et al. (Angel et al. 2012). Sections were submerged and re-submerged in chilled $150 \mathrm{mM}$ Ammonium Formate $\left(\mathrm{NH}_{4} \mathrm{HCO}_{2}\right) 10$ times over 20 seconds. Excess solution was removed by tapping slides gently on their long axis before resubmerging in identical fresh solution for an additional 5 dips over 10 seconds.
Excess solution was again removed by gently tapping the slides on their long axis. Each slide was washed separately with fresh solutions and dried in a vacuum desiccator for 1 hour.

\section{Sublimation:}

DHB was chosen as the matrix for MALDI MSI analysis. $5.5 \mathrm{mg}$ of DHB was dissolved in $200 \mu \mathrm{L}$ of acetone and dispensed over a $90 \mathrm{~mm}$ diameter aluminium foil circle. Solvent was evaporated over a $40^{\circ} \mathrm{C}$ hot plate until matrix formed a dry thin layer. Sublimation was achieved using an Ace Glass sublimation chamber (Ace Glass Incorporated, NJ, USA) with a vacuum pump (Christ) set to 0.12 mbar (ice-condenser $-86^{\circ} \mathrm{C}$ ). DHB was sublimated for 10 minutes from the time the heating mantel was switched on, the mantel maximum temperature was set to $120^{\circ} \mathrm{C}$.

\section{Matrix recrystallisation:}

Using a method adapted from Morikawa-Ichinose et al. (Morikawa-Ichinose et al. 2019) the matrix on the microscope slide was allowed to recrystallise in a glass slide staining trough (dimensions $=15 \mathrm{~cm} \times 7.5 \mathrm{~cm} \times$ $8.5 \mathrm{~cm}$ ). The trough was prepared by adding $300 \mu \mathrm{L}$ of methanol: water $(5: 95 \mathrm{v} / \mathrm{v})$ into the glass chamber, which was then covered. The chamber was pre-warmed in an oven (Hybaid) set to $60^{\circ} \mathrm{C}$. Immediately following sublimation slides were placed in a glass slide holder and lowered into the chamber for 90 seconds.

\section{MALDI Profiling:}

The suppressive effect of O.C.T. containing PEG was evaluated using lipid standards and a ground steel MALDI target plate (Bruker, Bremen, Germany) and a method adapted from Bruker's guide to MALDI sample preparation. Each lipid standard (PC [17:0/17:0]) (SM [d18:1/16:0]) (Avanti Polar Lipids (AL, USA)) were made to $1 \mu \mathrm{g} / \mathrm{mL}$ in TA30 solvent $(70: 30 \quad[\mathrm{v} / \mathrm{v}]$ acetonitrile: $0.1 \%$ TFA in water). O.C.T. was diluted $1: 10$ (v:v) in $0.1 \%$ TFA and then further diluted to final dilutions of $1: 100(\mathrm{v}: \mathrm{v})$ and $1: 1000(\mathrm{v}: \mathrm{v})$ with TA 30 solvent. Lipid standards $(1 \mu \mathrm{g} / \mathrm{mL})$ were mixed $1: 10$ with each O.C.T. dilution and mixed 1:1 with DHB matrix solution $(20 \mathrm{mg} / \mathrm{mL}$ in TA30 solvent) a $0.5 \mu \mathrm{L}$ spot was deposited onto the MALDI target plate and once dried, $0.5 \mu \mathrm{L}$ of $100 \%$ acetone was deposited onto the sample spots to allow analyte/matrix re-crystallisation. Profiling was then achieved using the following method: the full $\mathrm{m} / \mathrm{z}$ 100-1250 mass range in positive ion mode was analysed for consistency with the MALDI imaging experiments. A $50 \mu \mathrm{m}$ laser step size was used with 1000 shots at $40 \%$ laser energy to generate a profile spectrum from each co-ordinate on the MALDI target plate. A region of $2 \mathrm{~mm}$ in diameter was sampled per co-ordinate including a random raster movement with 200 shots per position for a total of 5 movements. 


\section{MALDI Imaging:}

Whole tissue sections from O.C.T. embedded Human prostate samples were imaged using a timsTOF FleX mass spectrometer (Bruker Daltonik, Bremen, Germany) with a $20 \mu \mathrm{m}$ pixel size and a $20 \mu \mathrm{m}$ laser step-size. For human prostate tissues $(n=4), 1$ washed and 1 un-washed section per patient were imaged using the following instrument parameters. An $\mathrm{m} / \mathrm{z}$ range of 100-1250 was analysed with 250 laser shots per pixel at $70 \%$ energy using the Bruker Smart3D laser system $(10 \mathrm{kHz})$ $(\mathrm{Nd}$ :YAG $355 \mathrm{~nm})$. All imaging work was performed in positive ion mode and mass calibration was achieved using Tune Mix (Agilent Technologies, CA, USA) in ESI mode. A rectangular strip of matched O.C.T. embedded and non-embedded, washed, and un-washed xenograft tissues $(n=1)$, were imaged using the same method.

\section{MALDI MS/MS:}

Acquisition of MS/MS data for lipid identification was performed on a timsTOF FleX mass spectrometer in positive ion mode using a precursor ion isolation width of $1.5 \mathrm{Da}$ for each $\mathrm{m} / \mathrm{z}$ interval analysed. A low collision energy $(3.0 \mathrm{eV})$ and elevated collision energy $(35 \mathrm{eV})$ acquisition was generated for each precursor ion. Instrument parameters were identical to imaging experiments apart from increased laser spot size to $50 \mu \mathrm{m}$ and laser energy decreased to $60 \%$. MS/MS calibration was performed in ESI mode using Sodium Formate $\left(\mathrm{NaHCO}_{2}\right)$.

\section{Data Processing:}

MALDI imaging data was processed using SCiLS Lab 2020a (Bruker, Bremen, Germany) as follows. Peaks from all mean spectra were moved to local maximum and the data was normalised to total ion count (TIC). Peak list annotations were generated by exporting regions of interest to Metaboscape 5.0 (Bruker, Bremen, Germany) and by searching $\mathrm{m} / \mathrm{z}$ values against the LIPID MAPS database. Tentative species identifications were accepted if $\Delta \mathrm{m}<10 \mathrm{mDa}$. MS/MS and MALDI profiling data was processed and analysed using Data Analysis (Bruker, Bremen, Germany).

\section{H\&E Staining:}

Matrix was removed from the imaged tissue sections by running methanol over the slides. Slides were first gently submerged in a water bath with slow running water. Slides were removed from the bath and stained for 30 seconds with filtered Lillie Mayer's Haematoxylin, excess haematoxylin was removed in running water for 30 seconds before differentiation in $1 \%$ acid alcohol for 5 seconds. Slides were placed back in running water until clear followed by 10 seconds in a saturated aqueous carbonate solution and again washed in running water. Tissue sections were counterstained in filtered $1 \%$ alcoholic eosin for 20 seconds. Stained slides were dehydrated in a series of ethanol solutions and cleared in xylene before cover slipping with DPX mounting media.

\section{Results and Discussion:}

\section{Lipid Suppression by Polyethylene Glycols (PEG):}

O.C.T. is a commonly used embedding medium for biological samples. Its ability to maintain tissue integrity and stability at temperatures between $-20^{\circ} \mathrm{C}$ and $-80^{\circ} \mathrm{C}$ make it ideal for long periods of storage. Furthermore, as O.C.T. is a solid at typical cryostat sectioning temperatures, it provides a smooth surface by which quality sections can be acquired for histology (Schwartz, Reyzer \& Caprioli 2003). An undesirable effect of this process is that O.C.T. can be spread across the surface of the tissue and cause ion suppression by PEG polymers during MS experiments (Schwartz, Reyzer \& Caprioli 2003). However, as bio-banked O.C.T. embedded tissues are abundant, and access to alternatives may be scarce for some, imaging studies using O.C.T. embedded tissues have still been attempted with lipid ions still being detected. One group imaging prostate cancer tissues in positive ion mode reported that O.C.T. contamination only affected segmentation analysis, whereby regions of O.C.T. surrounding the tissue were clustered together (Randall et al. 2019), while another group imaging in negative ion mode stated that there was no significant difference between mass spectrum quality and number of lipids identified, and that MALDI MSI of O.C.T. embedded tissues was compatible with negative ion mode imaging (Goto et al. 2014). The mechanism by which the presence of PEG results in suppression of analyte signal intensity in MALDI is unclear, however the consensus appears to be that the polymer competes with analyte molecules for available charge within the ion plume after laser ablation, preventing ion transfer from matrix molecules to analyte gas-phase molecules. To directly observe and quantify this effect, two lipid standards - SM (d18:1/16:0) and PC (17:0/17:0) - at a concentration of $1 \mu \mathrm{g} / \mathrm{mL}$ were mixed with O.C.T. and spotted onto a ground steel MALDI target plate (Figure 1d). A significant reduction in the signal intensity of each standard was observed in the profile mass spectrum when diluted with O.C.T. at a concentration of 1:100 (Figure 2 a-b). PEG ions were detected in the $\mathrm{m} / z$ 900-1250 range (Supplementary Figure S1) which resulted in a 16-fold and 27-fold decrease in signal intensity for PC (17:0/17:0) and SM (d18:1/16:0) respectively (Table 1). The degree of suppression was variable between the two lipid classes, suggesting the extent of analyte suppression may be subject to each molecule's affinity for ionisation during the MALDI process. For example, phospholipid species in positive ion mode preferentially form adducts with cation species such as $\mathrm{Na}^{+}$(Wang, C, Wang \& Han 2015), a process facilitated by the transfer of free cations generated in the ion plume (Erb, Hanton \& Owens 2006; Zhang, J \& Zenobi 2004). 
Removal of O.C.T.:

To test whether maximum removal of O.C.T. could be achieved whilst maintaining tissue integrity and localisation of signal, 4 patients' prostate samples from men that had undergone a radical prostatectomy were embedded in O.C.T. and sectioned to $10 \mu \mathrm{m}$ thickness for MALDI MSI analysis (Figure 1c). Serial sections were taken allowing for un-washed and ammonium formate washed sections to be directly compared. This method was also replicated in prostate xenograft tissue samples (Figure 1b). PEG ions have a well characterised distribution with predictable peak intervals (44 Da separation) (Figure 3a) (Supplementary Figure S2), a feature that also makes them ideal for instrument mass calibration (Moskovets \& Karger 2003). Although PEG polymers are predominantly found at higher $\mathrm{m} / \mathrm{z}$ ranges $(>m / z$ 1500) where peptides and proteins are found (Schwartz, Reyzer \& Caprioli 2003; Strohalm et al. 2011; Weston \& Hummon 2013), small molecular weight PEG ions can still be detected in the low $\mathrm{m} / \mathrm{z}$ range $(<m / z$ 1500) (Strohalm et al. 2011). Indeed, these low mass PEG ions (base peak $\mathrm{m} / z$ 1201.653) were detected as a partial Gaussian distribution separated by $44 \mathrm{Da}$ intervals in the mean mass spectrum from unwashed O.C.T. embedded human prostate tissues (Figure 1a).

Additionally, each PEG ion had a similar distribution throughout the tissue (Figure 3c) (Supplementary Figure S2). A serial section from the same patient sample was taken and washed with $150 \mathrm{mM}$ ammonium formate prior to the application of MALDI matrix. This washing step successfully removed the characteristic PEG signal distribution from the mass spectrum of washed tissues (Figure 3b) in addition to rendering the distribution of the ions un-detectable in the resulting $\mathrm{m} / \mathrm{z}$ images (Figure 3d) (Supplementary Figure S2). Furthermore, the absolute intensity of each PEG ion in the regions of washed tissues imaged were below the limit of detection (B.L.O.D). This effect was observed for each of the PEG ions identified in this work and was consistent in both the regions of prostate xenograft tissue and the human tissues imaged (Tables $2 \& 3$ 3). This confirms that the washing procedure was efficient at removing O.C.T. to an adequate degree in which PEG ions became undetectable, was not preferentially removing one PEG ion over another, and that tissue type did not influence the effectiveness of the wash. Interestingly, the signal intensity of PEG ions detected in embedded tissues was consistently lower for xenograft tissues compared to human prostate tissues (data not shown), which suggests that the amount of O.C.T. spread on tissues after sectioning, and thus the degree of PEG suppression, potentially varies greatly between experiments and indeed between individual tissue sections. This variability plausibly explains why some studies have reported that O.C.T. from their embedded samples did not interfere with analyte detection or data analysis (Goto et al. 2014) while others have (Randall et al. 2019).

Ideally, complete removal of O.C.T. is desired to maximally restore analyte signal. However, aggressive washing technique had adverse effects on signal localisation. A leeching effect was observed when tissues were washed for 30 seconds in two fresh ammonium formate solutions (60 seconds total) and when washing solution was directly dispensed onto the tissue. Lipid ions were found to be both delocalised within the tissue and in regions off tissue when compared to un-washed sections (Supplementary Figure S3), an effect that has also been reported by others for washing durations that exceed 30 seconds (Wang, HY, Liu \& Wu 2011). As such, a balance between maximum removal of O.C.T. and preservation of native analyte localisation must be considered when utilising a washing step during sample preparation. Furthermore, when choosing an appropriate washing solution, one should consider its compatibility with the analytes of interest. For example, previously reported methods for removing O.C.T. were implemented for proteomic analysis using liquid chromatography mass spectrometry (LC-MS), an MS modality where spatial information is not of concern (Jorge et al. 2019; Weston \& Hummon 2013). However, these methods involve more aggressive techniques and use organic based washing solutions such as ethanol. These methods would not be compatible with lipid imaging by MALDI MSI where preservation of analyte localisation is paramount.

Removal of Endogenous Salts by Ammonium Formate Washing:

Tissue washing prior to matrix application has become a popular addition to the sample preparation process for lipid imaging by MALDI MSI. Several washing solutions ranging from high-to-low organic content have been evaluated previously (Angel et al. 2012; Wang, HY, Liu \& Wu 2011) with reports of increased signal intensity and sensitivity (Angel et al. 2012; Wang, HY, Liu \& Wu 2011; Wang, HY et al. 2012; Zaima et al. 2014). The results of which indicate that water-based washing solutions containing organic salts have shown efficacy in improving signal intensity in addition to increasing overall number of peaks detected (Angel et al. 2012; de Macedo et al. 2015; de Macedo, Anderson \& Schey 2017; Wang, HY, Liu \& Wu 2011).

However, the compatibility of combining a washing procedure to remove organic salts in addition to contaminants such as O.C.T. for MALDI MSI is yet to be shown. To evaluate this compatibility, matched nonembedded prostate xenograft tissues were analysed, with un-washed and washed serial sections being directly compared (Figure 1a). This process was repeated in unwashed and washed O.C.T. embedded serial sections to confirm compatibility with O.C.T. removal. During the analysis, a list of six phosphatidylcholines (PC), two 
lyso-phosphatidylcholines (LPC) and one sphingomyelin (SM) with $\mathrm{H}^{+}, \mathrm{Na}^{+}$and $\mathrm{K}^{+}$adducts were identified by importing measured $\mathrm{m} / \mathrm{z}$, values into the LIPID MAPS database and chosen for comparison between un-washed and washed samples (Supplementary Table S1). These identifications were then confirmed by MS/MS (Supplementary Figure S4).

A primary benefit of tissue washing prior to matrix application is increasing the number of detected analytes in addition to increasing signal intensity. This concept has been reported previously for analysis of proteins (Schwartz, Reyzer \& Caprioli 2003) and lipid profiling by MALDI MS (Wang, HY, Liu \& Wu 2011), and lipid imaging by MALDI MSI (Angel et al. 2012; Wang, HY et al. 2012; Zaima et al. 2014). In positive ion mode analysis, the $\mathrm{m} / \mathrm{z}, 600-900$ mass range is dominated by PCs and SMs forming a range of different cation adducts (Figure 4). In general, each lipid identified was detectable as $\mathrm{H}^{+}, \mathrm{Na}^{+}$and $\mathrm{K}^{+}$adducts in both un-washed (Figure 4 [bottom]) and washed (Figure 4 [top]) tissues from xenograft and human prostate tissues (Supplementary Table S2). In washed xenograft tissues, the S/N ratio for protonated PC, LPC and SM species was significantly higher compared to un-washed serial sections, while the $\mathrm{S} / \mathrm{N}$ ratio for the corresponding $\mathrm{Na}^{+}$and $\mathrm{K}^{+}$adducts was significantly lower. The opposite was observed for un-washed tissues with $\mathrm{Na}^{+}$ and $\mathrm{K}^{+}$adducts of each lipid being detected with increased intensity compared to protonated species. For example, protonated PC 32:0 $(\mathrm{m} / \mathrm{z}$ 734.568) and SM d18:1/16:0 $(\mathrm{m} / \mathrm{z}$ 703.575) were the dominant peaks detected in the washed tissue (Figure 4 [top]), while the $\mathrm{Na}^{+}\left(m / z, 756.555\right.$ and $m / z 725.558$ respectively) and $\mathrm{K}^{+}$ $(\mathrm{m} / z 772.527$ and $m / z 741.531$ respectively) adducts were the dominant species detected in un-washed tissues (Figure 4 [bottom])(Supplementary Table S2). Most importantly, the washing process did not remove any of the lipid species detected, as all 9 were still detectable in washed tissues, albeit predominantly in protonated form. From a mass spectrum perspective, washing tissues for the purpose of improving spectrum simplicity and S/N ratio may be beneficial for identifying lipids present in low abundance. The number of ions detected for a specific lipid species will be represented predominantly by the protonated peaks rather than split between multiple adducts, allowing for improved sensitivity, signal intensity and more confidence in identifying significant peaks.

The ability to spatially resolve and identify the localisation and abundance of analytes in tissue is a fundamental characteristic that separates MSI from other MS modalities. For the analysis of lipids by MALDI MSI in negative ion mode, washing tissues prior to the application of a matrix can remove endogenous salts and promote the formation of de-protonated adducts during ionisation (Angel et al. 2012). This process can also be applied to positive ion mode imaging (Angel et al. 2012; Wang, HY et al. 2012; Zaima et al. 2014), where $\mathrm{Na}^{+}$and
$\mathrm{K}^{+}$adducts are commonly observed as dominant peaks for PC and SM species (Leopold et al. 2018). Figure 5. illustrates the distribution and relative abundance of PC 32:0 and PC 34:2 detected in prostate xenograft tissues. Imaged in the positive ion mode, the sodium adducts of each lipid at $\mathrm{m} / \mathrm{z} 756.555$ (Figure 5c\&d) and $\mathrm{m} / \mathrm{z}$ 780.551 (Figure 5g\&h) respectively were detected with higher intensity and distinctive distributions in unwashed compared to washed tissues. Conversely the proton adducts at $\mathrm{m} / \mathrm{z} 734.568$ (Figure 5a\&b) and $\mathrm{m} / \mathrm{z}$ 758.569 (Figure 5e\&f) were more detectable in tissues washed with ammonium formate. Indeed, the effect brought about by washing was consistent in all 9 lipid species analysed, with both $\mathrm{Na}^{+}$and $\mathrm{K}^{+}$lipid adducts being more prominent in un-washed tissues while protonated species were dominant in washed tissues (Supplementary Table 3) suggesting that PCs, SMs and LPCs may preferentially form cation adducts rather than protonated species. At the concentration of $150 \mathrm{mM}$ used in this study, ammonium formate wash appears to significantly remove tissue salts available for adduct ion formation. However, for high abundance lipids in tissues, such as those comprised of fatty acids with $\mathrm{C}_{16}, \mathrm{C}_{18}$ and $\mathrm{C}_{20}$ chain lengths, a small residual amount of signal was still observed for $\mathrm{Na}^{+}$and $\mathrm{K}^{+}$adducts in washed tissues (Figure 5). Suggesting that complete desalting of endogenous $\mathrm{Na}^{+}$and $\mathrm{K}^{+}$was not achieved. This detail must be considered when interpreting mass spectra from de-salted samples, and good practice should still entail considering all adduct ions as representative peaks of a certain lipid upon initial assessment of the data.

A significant challenge faced by researchers when interpreting mass spectra and characterising the distribution of lipid ions is the presence of isobaric species. Consequently, identifications based on $\mathrm{m} / \mathrm{z}$ measurements alone are considered tentative without additional experiments like MS/MS. MALDI MSI data constructs 2D maps of ion distributions, however isobaric or near-isobaric species can generate overlapping distributions making data interpretation difficult. PC $34: 1[\mathrm{M}+\mathrm{Na}]^{+}$and PC $36: 4[\mathrm{M}+\mathrm{H}]^{+}$is such an example of near-isobaric species with theoretical $\mathrm{m} / \mathrm{z}$ values of $m / z 782.5670$ and $m / z 782.5694$ respectively, and achieving baseline separation of these peaks would require a resolution of approximately 800,000 (FWHM) at $m / z, 782$ to baseline resolve these masses. This is unobtainable with the instrument used in this study, and indeed with all current generation TOF mass analysers. In prostate xenograft tissue, the peak at $\mathrm{m} / z, 782.5697$ and the resulting distribution of the ion in un-washed samples is a composite of both lipid species. The presence of PC 34:1 (16:0/18:1) $[\mathrm{M}+\mathrm{Na}]^{+}$was confirmed by MS/MS, fragment ions were identified as fatty acids 16:0+18:1+glycerol $(\mathrm{m} / \mathrm{z}$ 599.4990) (Figure 6a. [b]), LPC 18:1 [M+Na] ${ }^{+}(\mathrm{m} / \mathrm{z}, 526.3290)$ (Figure 6a. [c]) and the PC head group minus $\mathrm{C}_{3} \mathrm{H}_{9} \mathrm{~N}$ (Figure 6a. [a-b']), with the latter being a characteristic fragment ion of PCs $[\mathrm{M}+\mathrm{Na}]^{+}$. Furthermore, the presence of PC $36: 4[\mathrm{M}+\mathrm{H}]^{+}$ was confirmed by the fragment ion at $\mathrm{m} / \mathrm{z} \quad 184.079$ 
(Figure 6a [a]), as this ion corresponds to the protonated un-fragmented PC head group. This confirms that the signal observed at $\mathrm{m} / \mathrm{z} 782.5697$ in MALDI MSI was most likely a mixture, and that the resulting $\mathrm{m} / \mathrm{z}$ image (Figure 6b) represented the combined distributions of both lipids. Washing with ammonium formate removes endogenous salts such as $\mathrm{Na}^{+}$and $\mathrm{K}^{+}$and promotes protonated ions. In washed tissues, MS/MS confirmed that the ion detected at $m / z 782.5697$ contained only the protonated lipid PC 36:4 $[\mathrm{M}+\mathrm{H}]^{+}$as the fragment ions detected corresponded to LPC 16:0 $[\mathrm{M}+\mathrm{H}]^{+}$(Figure 6c [c]) and the protonated PC head group (Figure 6c [a]). Moreover, the localisation of the ion in washed tissues (Figure 6d) differed in comparison to un-washed serial sections, further confirming that the overlapping distributions had been resolved by the removal of endogenous salts, preventing the formation of PC 34:1 $[\mathrm{M}+\mathrm{Na}]^{+}$.

Due to the large amount of data generated by MALDI MSI, multivariate statistical analyses are commonly used to compress and mine data in short amounts of time. These statistical approaches can include un-supervised data mining such as bisecting $k$-means segmentation and principal component analyses (PCA) in addition to supervised methods including receiver operator characteristics curves (ROC) and partial least squares discrimination analysis (PLS-DA) (Buchberger et al. 2018). Confidence in these analyses is derived from knowing the true distribution of molecules of interest, which makes high resolution data and high mass accuracy essential for mapping distributions of lipids with precision. However, a consideration rarely made is how variable salt concentration and distribution can be between different tissues and indeed within the same tissue section, and how that may influence the distribution visualised in the MALDI MSI data. In this study the spatial localisation of lipid ions with $\mathrm{H}^{+}, \mathrm{Na}^{+}$ and $\mathrm{K}^{+}$adducts were analysed and compared in prostate tissues. Throughout the data sets there were noticeably different distributions observed for $\mathrm{Na}^{+}$adducts within the same tissue sections compared to $\mathrm{H}^{+}$and $\mathrm{K}^{+}$ counterparts (Supplementary Figure S5). Previously, using magnetic resonance imaging (MRI), the distribution of sodium and its change in prostate cancer was evaluated (Barrett et al. 2018; Broeke et al. 2019), with one study finding that changes in tissue sodium concentration (TSC) were present between tumour and non-tumour regions and between different zones of the prostate (Barrett et al. 2018) while another study reported that increasing changes in TSC were found in patients with higher risk disease. Therefore, regions of high $\mathrm{Na}^{+}$ concentration could explain the disparity observed in the distribution of $[\mathrm{M}+\mathrm{Na}]^{+}$lipid ions in this study, as the ratio between $\mathrm{Na}+, \mathrm{K}+$ and $\mathrm{H}+$ adducts formed will depend on a combination of the $\mathrm{H}+-, \mathrm{Na}+-$ and $\mathrm{K}+-$ affinity of the lipid and the relative concentrations of these ions. This effect has been observed previously in ischemic rat brain sections, ischemia results in an increase in tissue sodium and decrease in potassium.
Wang et al. reported a shift from $\mathrm{K}^{+}$and $\mathrm{H}^{+} \mathrm{PC}$ adducts to predominantly $\mathrm{Na}^{+}$species (Wang, $\mathrm{HY}$ et al. 2010). Hence, desalting tissues prior to lipid imaging by MALDI MSI not only improves sensitivity and signal intensity for protonated adduct ions but may also prevent distortion of spatial distribution information produced by variation in salt content between analyses.

Evidently, desalting tissues with a washing solution prior to matrix application benefits in several ways, including but not limited to improving sensitivity (Angel et al. 2012; Wang, HY, Liu \& Wu 2011), signal intensity and resolving isobaric species to reveal true molecular distributions. However, forming alkali metal cation adducts may also be beneficial for lipid identification. For all 9 lipids analysed in this study, more fragment ions were produced from metal cation adducts compared to protonated ions, allowing for confident identifications of molecular species (Supplementary Figure S4). Therefore, pushing ion formation towards protonated adducts may not be ideal for discovery studies using MALDI MSI. Alternatively, doping either washing solutions or matrix solutions with known cations may present a potential middle ground, as endogenous salts can be removed and replaced with known cations which can yield more structural information during MS/MS. Matrix doping has already been implemented by groups using lithium, sodium or potassium salts in matrix solutions (Cerruti et al. 2011; Dufresne et al. 2019; Zaima et al. 2014), which generate more homogenous distribution of cations across the tissue and significantly improve the detection of cation adducts. Additionally, desalting and doping tissues with potassium acetate has been shown to significantly increase detection of PC 34:1 $[\mathrm{M}+\mathrm{K}]^{+}$(Zaima et al. 2014). Phospholipids preferentially form adducts with lithium ions compared to other cations and dissociate into more detectable fragment ions during MS/MS (Cerruti et al. 2011). Therefore, lithium doping in a washing protocol as described in this study may circumvent the limitation of little fragmentation information produced by protonated lipids.

\section{Conclusion:}

We have shown that the desalting process and removal of O.C.T. contamination achieved by washing tissues with $150 \mathrm{mM}$ ammonium formate prior to matrix application are compatible with lipid imaging by MALDI MSI and can be achieved in the same washing step. Furthermore, it has been demonstrated that the removal of O.C.T. renders PEG ions B.L.O.D, and that washing tissues for positive ion mode analysis increases the detection of protonated lipids, decreases the intensity of cation adducts detected and hence removes overlapping distributions created by isobaric species. This reproducible washing step can be seamlessly integrated into lipidomic studies using MALDI MSI, providing researchers with a solution to circumvent the issue of extensive O.C.T. embedding in bio-banked tissues. Our 
method will allow researchers in the mass spectrometry and biomedical field access to large scale cohorts for further analysis that have been previously avoided.

\section{Acknowledgements:}

The authors acknowledge funding from the Movember Foundation/Prostate Cancer Foundation of Australia (MRTA3) and the US Department of Defense (ID). The authors also wish to acknowledge the ACRF which funded the mass spectrometer used in this research by establishing the ACRF Centre for Integrated Cancer Systems Biology at SAHMRI. JXMT and JW are supported by a Postgraduate Scholarship from the University of Adelaide, LMB is supported by a Principal Cancer Research Fellowship awarded by Cancer Council's Beat Cancer project on behalf of its donors, the State Government through the Department of Health and the Australian Government through the Medical Research Future Fund.

\section{References:}

Andersen, MK, Krossa, S, Høiem, TS, Buchholz, R, Claes, BSR, Balluff, B, Ellis, SR, Richardsen, E, Bertilsson, H, Heeren, RMA, Bathen, TF, Karst, U, Giskeødegård, GF \& Tessem, MB 2020, 'Simultaneous Detection of Zinc and Its Pathway Metabolites Using MALDI MS Imaging of Prostate Tissue', Anal Chem, vol. 92, no. 4, Feb 18, pp. 3171-3179.

Angel, PM, Spraggins, JM, Baldwin, HS \& Caprioli, R 2012, 'Enhanced sensitivity for high spatial resolution lipid analysis by negative ion mode matrix assisted laser desorption ionization imaging mass spectrometry', Anal Chem, vol. 84, no. 3, Feb 7, pp. 1557-1564.

Barrett, T, Riemer, F, McLean, MA, Kaggie, J, Robb, F, Tropp, JS, Warren, A, Bratt, O, Shah, N, Gnanapragasam, VJ, Gilbert, FJ, Graves, MJ \& Gallagher, FA 2018, 'Quantification of Total and Intracellular Sodium Concentration in Primary Prostate Cancer and Adjacent Normal Prostate Tissue With Magnetic Resonance Imaging', Invest Radiol, vol. 53, no. 8, Aug, pp. 450-456.

Berry, KA, Li, B, Reynolds, SD, Barkley, RM, Gijon, MA, Hankin, JA, Henson, PM \& Murphy, RC 2011, 'MALDI imaging MS of phospholipids in the mouse lung', J Lipid Res, vol. 52, no. 8, Aug, pp. 1551-1560.

Broeke, NC, Peterson, J, Lee, J, Martin, PR, Farag, A, Gomez, JA, Moussa, M, Gaed, M, Chin, J, Pautler, SE, Ward, A, Bauman, G, Bartha, R \& Scholl, TJ 2019, 'Characterization of clinical human prostate cancer lesions using 3.0-T sodium MRI registered to Gleason- graded whole-mount histopathology', J Magn Reson Imaging, vol. 49, no. 5, May, pp. 1409-1419.

Buchberger, AR, DeLaney, K, Johnson, J \& Li, L 2018, 'Mass Spectrometry Imaging: A Review of Emerging Advancements and Future Insights', Anal Chem, vol. 90, no. 1 , Jan 2, pp. 240-265.

Cerruti, CD, Touboul, D, Guérineau, V, Petit, VW, Laprévote, O \& Brunelle, A 2011, 'MALDI imaging mass spectrometry of lipids by adding lithium salts to the matrix solution', Anal Bioanal Chem, vol. 401, no. 1, Jul, pp. 75-87.

de Macedo, CS, Anderson, DM, Pascarelli, BM, Spraggins, JM, Sarno, EN, Schey, KL \& Pessolani, MC 2015, 'MALDI imaging reveals lipid changes in the skin of leprosy patients before and after multidrug therapy (MDT)', J Mass Spectrom, vol. 50, no. 12, Dec, pp. 13741385 .

de Macedo, CS, Anderson, DM \& Schey, KL 2017, 'MALDI (matrix assisted laser desorption ionization) Imaging Mass Spectrometry (IMS) of skin: Aspects of sample preparation', Talanta, vol. 174, Nov 1, pp. 325335.

Dufresne, M, Patterson, NH, Norris, JL \& Caprioli, RM 2019, 'Combining Salt Doping and Matrix Sublimation for High Spatial Resolution MALDI Imaging Mass Spectrometry of Neutral Lipids', Anal Chem, vol. 91, no. 20, Oct 15, pp. 12928-12934.

Enthaler, B, Pruns, JK, Wessel, S, Rapp, C, Fischer, M \& Wittern, KP 2012, 'Improved sample preparation for MALDI-MSI of endogenous compounds in skin tissue sections and mapping of exogenous active compounds subsequent to ex-vivo skin penetration', Anal Bioanal Chem, vol. 402, no. 3, Jan, pp. 1159-1167.

Erb, WJ, Hanton, SD \& Owens, KG 2006, 'A study of gas-phase cationization in matrix-assisted laser desorption/ionization time-of-flight mass spectrometry', Rapid Commun Mass Spectrom, vol. 20, no. 14, pp. 2165-2169.

Flinders, B, Huizing, LRS, van Heerden, M, Cuyckens, F, Neumann, UP, van der Laan, LJW, Olde Damink, SWM, Heeren, RMA, Schaap, FG \& Vreeken, RJ 2018, 'Cross-Species Molecular Imaging of Bile Salts and Lipids in Liver: Identification of Molecular Structural Markers in Health and Disease', Anal Chem, vol. 90, no. 20, Oct 16, pp. 11835-11846.

Gill, EL, Yost, RA, Vedam-Mai, V \& Garrett, TJ 2017, 'Precast Gelatin-Based Molds for Tissue Embedding Compatible with Mass Spectrometry Imaging', Anal Chem, vol. 89, no. 1, Jan 3, pp. 576-580. 
Gode, D \& Volmer, DA 2013, 'Lipid imaging by mass spectrometry - a review', Analyst, vol. 138, no. 5, Mar 7, pp. 1289-1315.

Goto-Inoue, N, Hayasaka, T, Zaima, N \& Setou, M 2011, 'Imaging mass spectrometry for lipidomics', Biochim Biophys Acta, vol. 1811, no. 11, Nov, pp. 961-969.

Goto, T, Terada, N, Inoue, T, Kobayashi, T, Nakayama, K, Okada, Y, Yoshikawa, T, Miyazaki, Y, Uegaki, M, Utsunomiya, N, Makino, Y, Sumiyoshi, S, Yamasaki, T, Kamba, T \& Ogawa, O 2015, 'Decreased expression of lysophosphatidylcholine $(16: 0 / \mathrm{OH})$ in high resolution imaging mass spectrometry independently predicts biochemical recurrence after surgical treatment for prostate cancer', Prostate, vol. 75, no. 16, Dec, pp. 18211830.

Goto, T, Terada, N, Inoue, T, Nakayama, K, Okada, Y, Yoshikawa, T, Miyazaki, Y, Uegaki, M, Sumiyoshi, S, Kobayashi, T, Kamba, T, Yoshimura, K \& Ogawa, O 2014, 'The expression profile of phosphatidylinositol in high spatial resolution imaging mass spectrometry as a potential biomarker for prostate cancer', PLoS One, vol. 9, no. 2, p. e90242.

Jorge, S, Capelo, JL, LaFramboise, W, Dhir, R, Lodeiro, C \& Santos, HM 2019, 'Development of a Robust Ultrasonic-Based Sample Treatment To Unravel the Proteome of OCT-Embedded Solid Tumor Biopsies', $J$ Proteome Res, vol. 18, no. 7, Jul 5, pp. 2979-2986.

Leopold, J, Popkova, Y, Engel, KM \& Schiller, J 2018, 'Visualizing phosphatidylcholine via mass spectrometry imaging: relevance to human health', Expert Rev Proteomics, vol. 15, no. 10, Oct, pp. 791-800.

Longuespee, R, Alberts, D, Pottier, C, Smargiasso, N, Mazzucchelli, G, Baiwir, D, Kriegsmann, M, Herfs, M, Kriegsmann, J, Delvenne, P \& De Pauw, E 2016, 'A laser microdissection-based workflow for FFPE tissue microproteomics: Important considerations for small sample processing', Methods, vol. 104, Jul 15, pp. 154162.

Mallah, K, Quanico, J, Trede, D, Kobeissy, F, Zibara, K, Salzet, M \& Fournier, I 2018, 'Lipid Changes Associated with Traumatic Brain Injury Revealed by 3D MALDIMSI', Anal Chem, vol. 90, no. 17, Sep 4, pp. 1056810576.

Meisenbichler, C, Doppler, C, Bernhard, D \& Muller, T 2019, 'Improved matrix coating for positive- and negative-ion-mode MALDI-TOF imaging of lipids in blood vessel tissues', Anal Bioanal Chem, vol. 411, no. 15, Jun, pp. 3221-3227.

Morikawa-Ichinose, T, Fujimura, Y, Murayama, F, Yamazaki, Y, Yamamoto, T, Wariishi, H \& Miura, D 2019, 'Improvement of Sensitivity and Reproducibility for Imaging of Endogenous Metabolites by MatrixAssisted Laser Desorption/Ionization-Mass Spectrometry', J Am Soc Mass Spectrom, vol. 30, no. 8, Aug, pp. 1512-1520.

Moskovets, E \& Karger, BL 2003, 'Mass calibration of a matrix-assisted laser desorption/ionization time-of-flight mass spectrometer including the rise time of the delayed extraction pulse', Rapid Commun Mass Spectrom, vol. 17, no. 3, pp. 229-237.

Mounfield, WP, 3rd \& Garrett, TJ 2012, 'Automated MALDI matrix coating system for multiple tissue samples for imaging mass spectrometry', J Am Soc Mass Spectrom, vol. 23, no. 3, Mar, pp. 563-569.

Randall, EC, Zadra, G, Chetta, P, Lopez, BGC, Syamala, S, Basu, SS, Agar, JN, Loda, M, Tempany, CM, Fennessy, FM \& Agar, NYR 2019, 'Molecular Characterization of Prostate Cancer with Associated Gleason Score Using Mass Spectrometry Imaging', Mol Cancer Res, vol. 17, no. 5, May, pp. 1155-1165.

Rohrbach, TD, Boyd, AE, Grizzard, PJ, Spiegel, S, Allegood, J \& Lima, S 2020, 'A simple method for sphingolipid analysis of tissues embedded in optimal cutting temperature compound', J Lipid Res, vol. 61, no. 6, Jun, pp. 953-967.

Schwamborn, K 2012, 'Imaging mass spectrometry in biomarker discovery and validation', J Proteomics, vol. 75, no. 16, Aug 30, pp. 4990-4998.

Schwartz, SA, Reyzer, ML \& Caprioli, RM 2003, 'Direct tissue analysis using matrix-assisted laser desorption/ionization mass spectrometry: practical aspects of sample preparation', J Mass Spectrom, vol. 38, no. 7, Jul, pp. 699-708.

Shah, P, Zhang, B, Choi, C, Yang, S, Zhou, J, Harlan, R, Tian, Y, Zhang, Z, Chan, DW \& Zhang, H 2015, 'Tissue proteomics using chemical immobilization and mass spectrometry', Anal Biochem, vol. 469, Jan 15, pp. 27-33.

Strohalm, M, Strohalm, J, Kaftan, F, Krasny, L, Volny, M, Novak, P, Ulbrich, K \& Havlicek, V 2011, 'Poly[N(2-hydroxypropyl)methacrylamide]-based tissueembedding medium compatible with MALDI mass spectrometry imaging experiments', Anal Chem, vol. 83, no. 13, Jul 1, pp. 5458-5462.

Tian, Y, Bova, GS \& Zhang, H 2011, 'Quantitative glycoproteomic analysis of optimal cutting temperatureembedded frozen tissues identifying glycoproteins associated with aggressive prostate cancer', Anal Chem, vol. 83, no. 18, Sep 15, pp. 7013-7019.

Ucal, Y, Durer, ZA, Atak, H, Kadioglu, E, Sahin, B, Coskun, A, Baykal, AT \& Ozpinar, A 2017, 'Clinical applications of MALDI imaging technologies in cancer 
and neurodegenerative diseases', Biochim Biophys Acta Proteins Proteom, vol. 1865, no. 7, Jul, pp. 795-816.

Veloso, A, Fernandez, R, Astigarraga, E, BarredaGomez, G, Manuel, I, Giralt, MT, Ferrer, I, Ochoa, B, Rodriguez-Puertas, R \& Fernandez, JA 2011, 'Distribution of lipids in human brain', Anal Bioanal Chem, vol. 401, no. 1, Jul, pp. 89-101.

Wang, C, Wang, M \& Han, X 2015, 'Applications of mass spectrometry for cellular lipid analysis', Mol Biosyst, vol. 11, no. 3, Mar, pp. 698-713.

Wang, HY, Liu, CB \& Wu, HW 2011, 'A simple desalting method for direct MALDI mass spectrometry profiling of tissue lipids', J Lipid Res, vol. 52, no. 4, Apr, pp. 840-849.

Wang, HY, Liu, CB, Wu, HW \& Kuo, JS 2010, 'Direct profiling of phospholipids and lysophospholipids in rat brain sections after ischemic stroke', Rapid Commun Mass Spectrom, vol. 24, no. 14, Jul 30, pp. 2057-2064.

Wang, HY, Wu, HW, Tsai, PJ \& Liu, CB 2012, 'MALDImass spectrometry imaging of desalted rat brain sections reveals ischemia-mediated changes of lipids', Anal Bioanal Chem, vol. 404, no. 1, Jul, pp. 113-124.

Weston, LA \& Hummon, AB 2013, 'Comparative LCMS/MS analysis of optimal cutting temperature (OCT) compound removal for the study of mammalian proteomes', Analyst, vol. 138, no. 21, Nov 7, pp. 63806384.

Zaima, N, Yoshioka, S, Sato, Y, Shinano, S, Ikeda, Y \& Moriyama, T 2014, 'Enhanced specificity for phosphatidylcholine analysis by positive ion mode matrix-assisted laser desorption/ionization imaging mass spectrometry', Rapid Commun Mass Spectrom, vol. 28, no. 13 , Jul 15, pp. 1453-1458.

Zhang, J \& Zenobi, R 2004, 'Matrix-dependent cationization in MALDI mass spectrometry', J Mass Spectrom, vol. 39, no. 7, Jul, pp. 808-816.

Zhang, W, Sakashita, S, Taylor, P, Tsao, MS \& Moran, MF 2015, 'Comprehensive proteome analysis of fresh frozen and optimal cutting temperature (OCT) embedded primary non-small cell lung carcinoma by LC-MS/MS', Methods, vol. 81, Jun 15, pp. 50-55. 


\section{Schematic Figure}

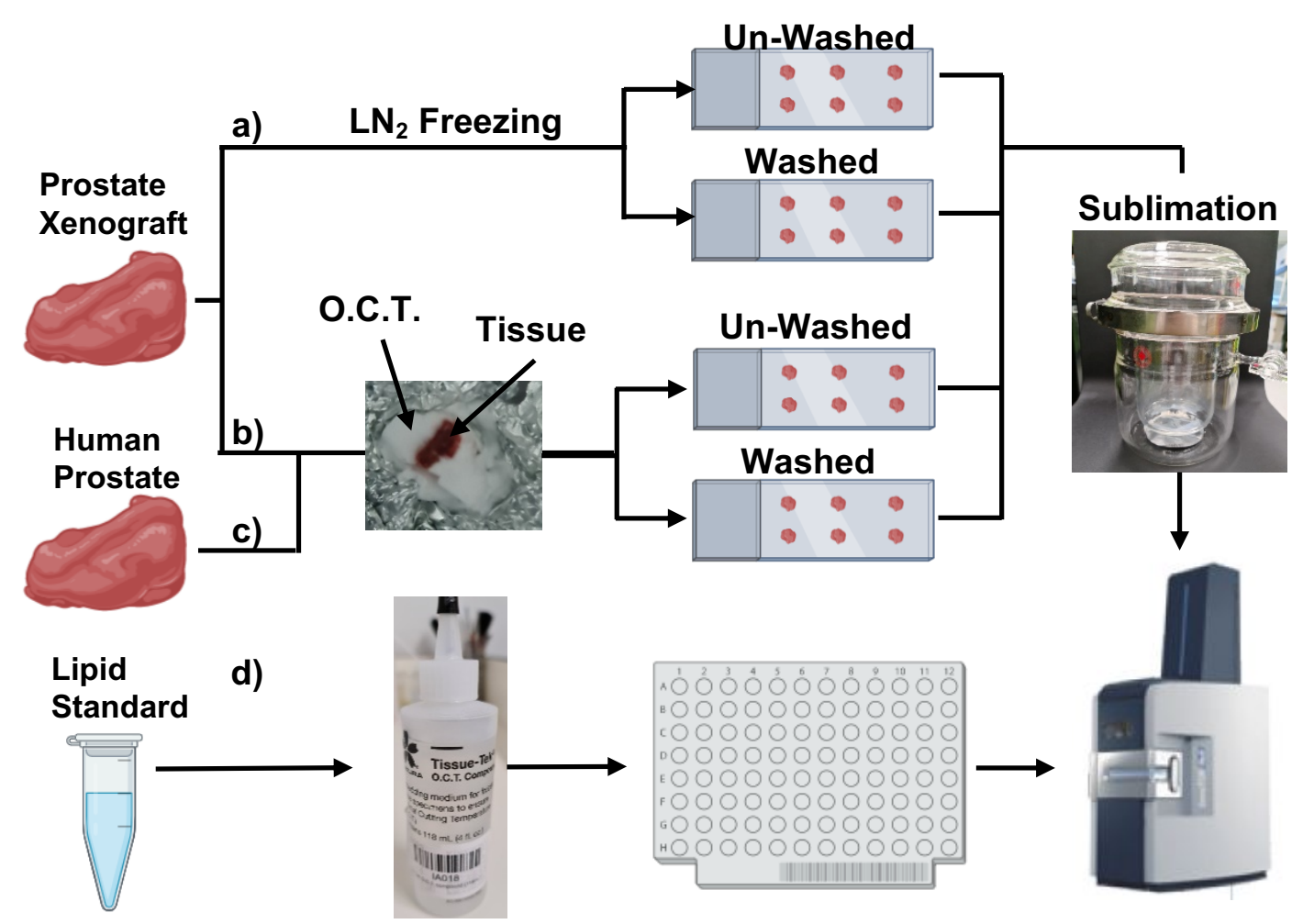

Fig 1. Schematic of experimental approach. Prostate xenograft samples were bisected with one half embedded in O.C.T. and one half snap frozen in liquid $\mathrm{N}_{2}$. Human prostate samples were embedded in O.C.T. Human (b) and xenograft (c) prostate tissues embedded and cut with serial un-washed and washed sections imaged to evaluate the removal of O.C.T. contamination. Un-embedded prostate xenograft tissues (a) were cut with serial un-washed and washed sections imaged to test the desalting effect of ammonium formate. All imaging work was performed in positive ion mode with a pixel size of $20 \mu \mathrm{m}$ and $20 \mu \mathrm{m}$ raster width. Each mass spectrum was acquired between $m / z$ 100-1250. The suppressive effect of O.C.T. was measured by spotting a mixture of lipid standards and O.C.T. onto a ground steel MALDI target plate. 


\section{Figure 2}
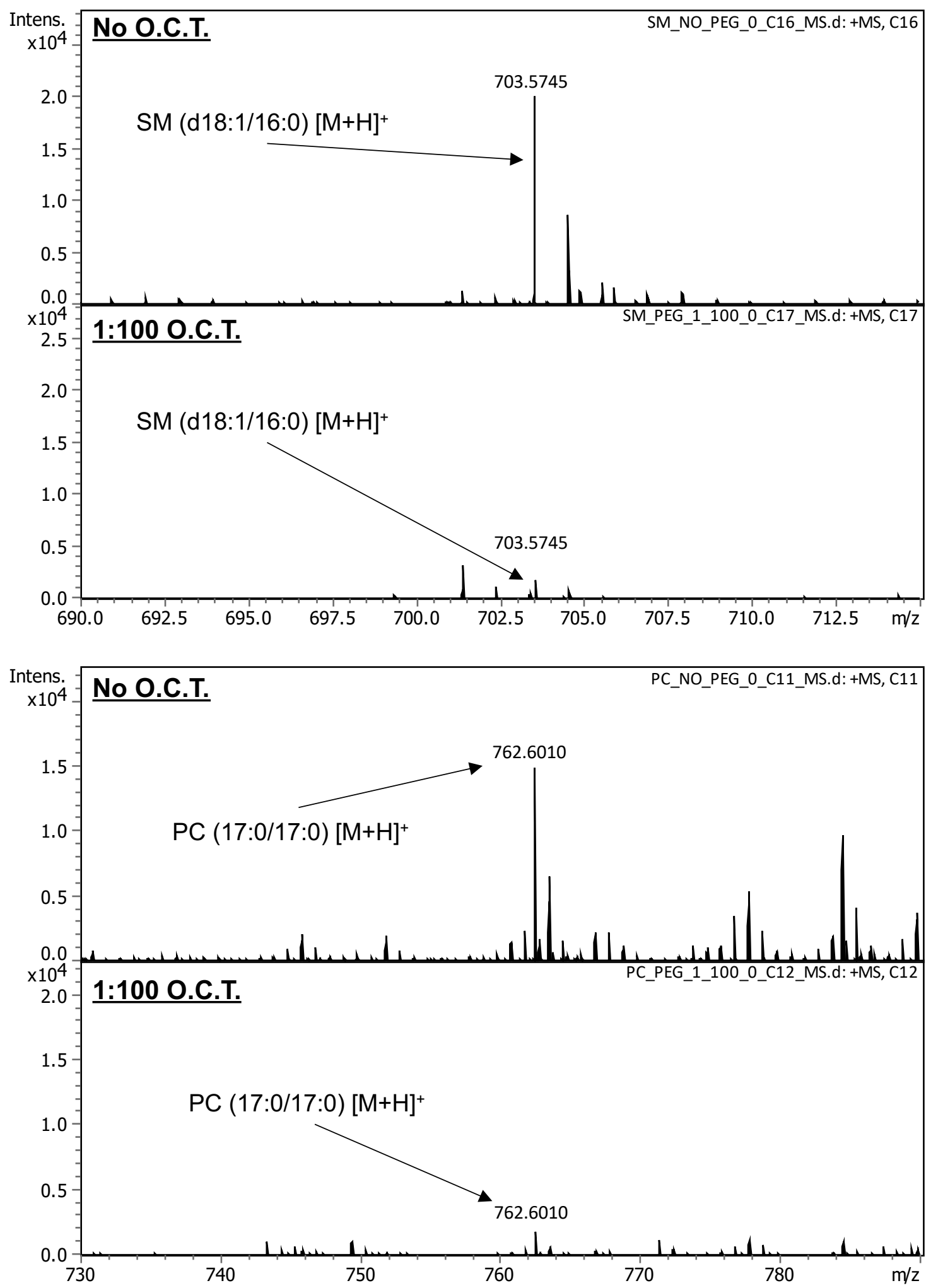

Figure 2. Mass spectrum showing the change in signal intensity of protonated lipid standards a) SM (d18:1/16:0) (Theoretical $\mathrm{m} / z$ 703.575) and b) PC (17:0/17:0) (Theoretical $\mathrm{m} / z$ 762.601) after dilution with O.C.T. $0.5 \mu \mathrm{L}$ of Lipid/O.C.T. mixture was deposited on a ground steel MALDI target plate. Profiling was performed in positive ion mode within $\mathrm{m} / \mathrm{z}$ 100-1250. 


\section{Figure 3}

a)

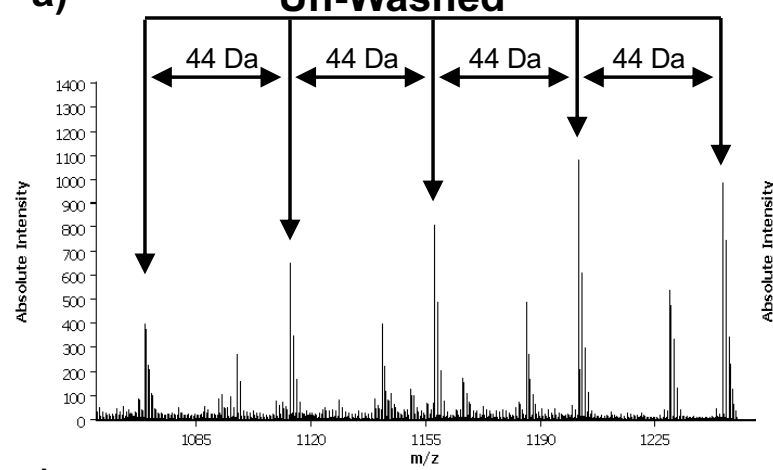

c)

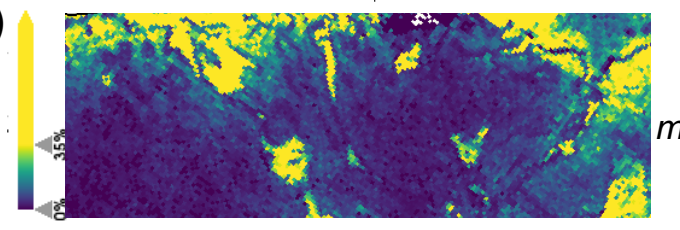

e)

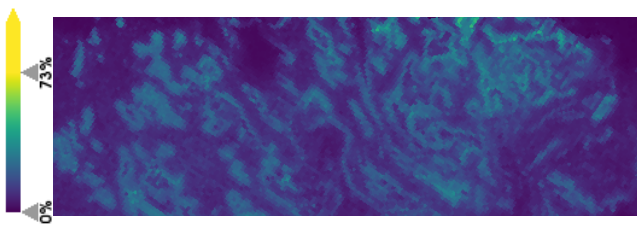

g)

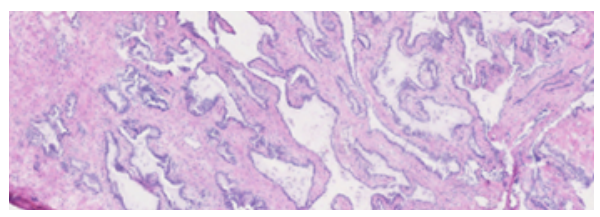

b)

Washed

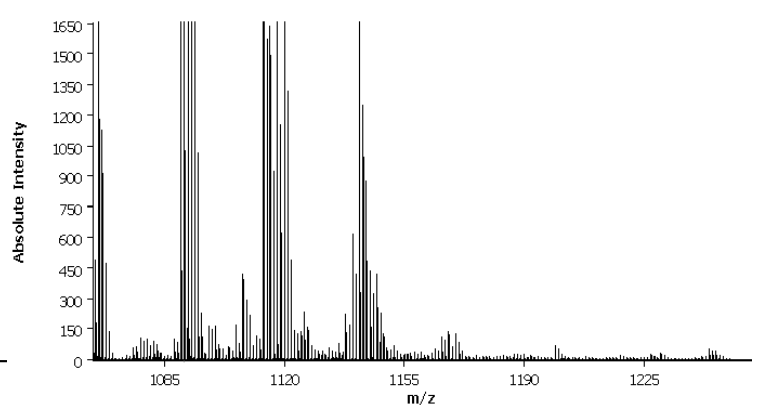

PEG

$\mathrm{m} / \mathrm{z} 1201.653$
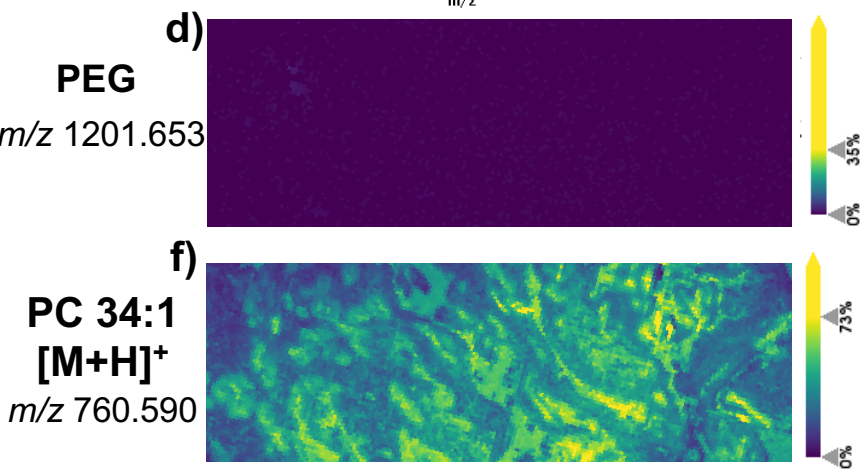

h)

\section{H\&E to be added}

Figure 3. Mean mass spectrum from un-washed a) and washed b) human prostate tissues showing the absolute intensity of PEG ion peaks in the $\mathrm{m} / \mathrm{z}$ 1050-1250 range. c), d) $\mathrm{m} / \mathrm{z}$ image revealing the spatial localization of a single PEG ion ( $m / z$ 1201.653) in un-washed c) and washed d) tissues. e,f) $m / z$ image of the distribution of protonated PC 34:1 ( $\mathrm{m} / \mathrm{z}$ 760.590) in un-washed e) and washed f) samples. MALDI imaged tissues stained with H\&E g,h). Images were acquired in positive ion mode using a raster width of $20 \mu \mathrm{m}$ and a $20 \mu \mathrm{m}$ pixel size. Image colour scale bar shows intensity (a.u.) Physical scale bar indicates $800 \mu \mathrm{m}$. 
Table 1. Change in signal intensity of lipid standards detected after diluting with 1/100 O.C.T.

\begin{tabular}{lccccc}
\hline Lipid Standard Adduct lon & $\begin{array}{c}\text { Theoretical } \\
\mathbf{m} / \mathbf{z}\end{array}$ & No O.C.T. & $\begin{array}{c}\text { S.C.T. } \\
(\mathbf{1} / 100)\end{array}$ & $\begin{array}{c}\text { Fold } \\
\text { Change }\end{array}$ \\
\hline $\mathrm{PC}(17: 0 / 17: 0)$ & {$[\mathrm{M}+\mathrm{H}]^{+}$} & 762.601 & 26617 & 1691 & 16 \\
$\mathrm{SM}(\mathrm{d} 18: 1 / 16: 0)$ & {$[\mathrm{M}+\mathrm{H}]^{+}$} & 703.577 & 41877 & 1575 & 27 \\
\hline
\end{tabular}

Table 2. Change in signal intensity of low mass PEG ions between un-washed and washed O.C.T. embedded human prostate tissues. Intensity values derived from mean mass spectrum of regions.

\begin{tabular}{ccc}
\hline PEG ions & \multicolumn{2}{c}{ Signal Intensity (a.u) } \\
& O.C.T. Un-washed & O.C.T. Washed \\
\hline$m / z 1245.670$ & 989 & B.L.O.D. \\
$m / z 1201.653$ & 1082 & B.L.O.D. \\
$m / z 1157.639$ & 811 & B.L.O.D. \\
$m / z 1113.598$ & 652 & B.L.O.D. \\
$m / z 1069.586$ & 397 & B.L.O.D. \\
Average & 786 & B.L.O.D. \\
\hline
\end{tabular}

Table 3. Change in signal intensity of low mass PEG ions between un-washed and washed O.C.T. embedded prostate xenograft tissues. Intensity values derived from mean mass spectrum of regions.

\begin{tabular}{ccc}
\hline PEG ions & \multicolumn{2}{c}{ Signal Intensity (a.u) } \\
& O.C.T. Un-washed & O.C.T. Washed \\
\hline$m / z 1245.685$ & 181 & B.L.O.D. \\
$m / z 1201.658$ & 236 & B.L.O.D. \\
$m / z 1157.623$ & 140 & B.L.O.D. \\
$m / z 1113.605$ & 153 & B.L.O.D. \\
$m / z 1069.574$ & 124 & B.L.O.D. \\
Average & 167 & B.L.O.D. \\
\hline
\end{tabular}




\section{Figure 4}

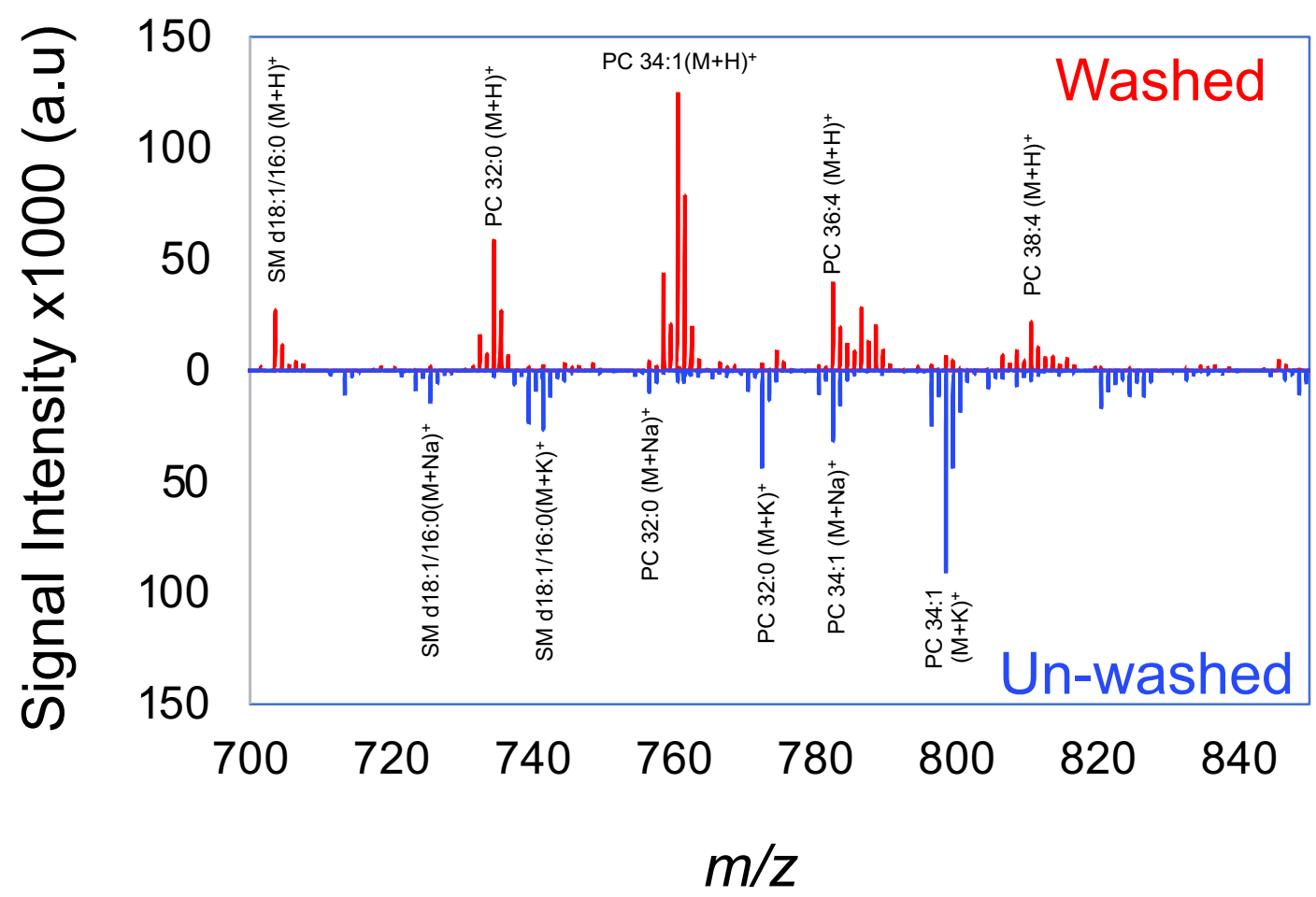

Figure 4. Mean mass spectrum from washed (top/red) and un-washed (bottom/blue) showing the $m / z$ 700-850 range dominated by PC and SM lipids in positive ion mode. Cation $\left(\mathrm{Na}^{+}\right.$and $\left.\mathrm{K}^{+}\right)$and protonated adduct ions from PC 32:0 and SM d1 8:1/16:0 in washed (top) and un-washed (bottom) are annotated. Mass spectra were acquired in positive ion mode within the full $\mathrm{m} / \mathrm{z}$ 100-1250 range using a $20 \mu \mathrm{m}$ raster width and pixel size from unembedded prostate xenograft tissue. 


\section{Figure 5}

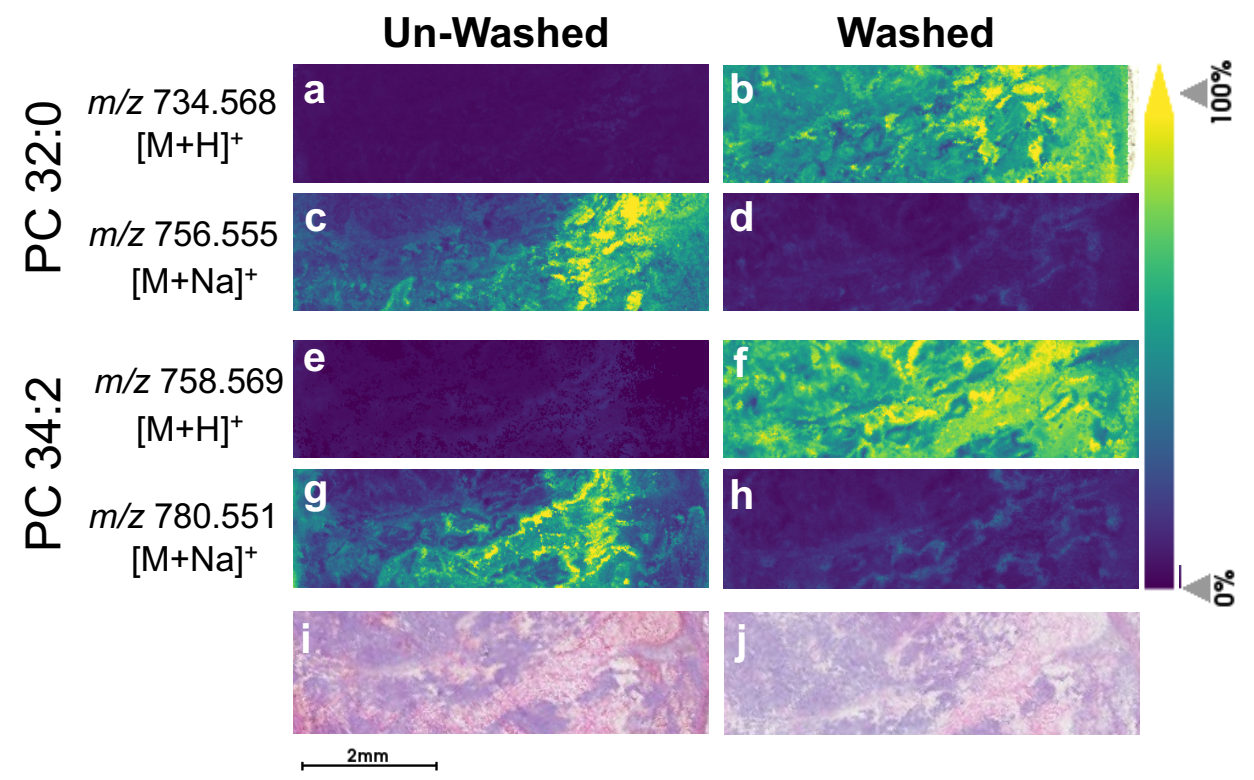

Figure 5. $20 \mu \mathrm{m}$ images of 2 phospholipids detected in un-washed (left) and ammonium formate washed (right) prostate xenograft tissues imaged in positive ion mode. a,b) $\mathrm{m} / \mathrm{z}$ images showing protonated adduct ions of PC 32:0 ( $\mathrm{m} / \mathrm{z} 734.568)$ and its sodiated equivalent $(\mathrm{m} / \mathrm{z} 756.555) \mathbf{c , d}) . \mathbf{e , f})$ $m / z$ images of protonated PC 34:2 ( $/ 2 / z 758.569)$ and its sodiated adduct ion $(\mathrm{m} / \mathrm{z}$ 780.551). Protonated adduct ions of each lipid were more detectable in tissues washed with ammonium formate $\mathbf{b , f}$ ) with sodiated counterparts more detectable in un-washed tissues $\mathbf{c}, \mathbf{g})$. MALDI imaged tissue sections stained with H\&E $\mathbf{i}, \mathbf{j})$. Image colour scale bar shows intensity (a.u.) 


\section{Figure 6.}

\section{a) Un-washed b)}
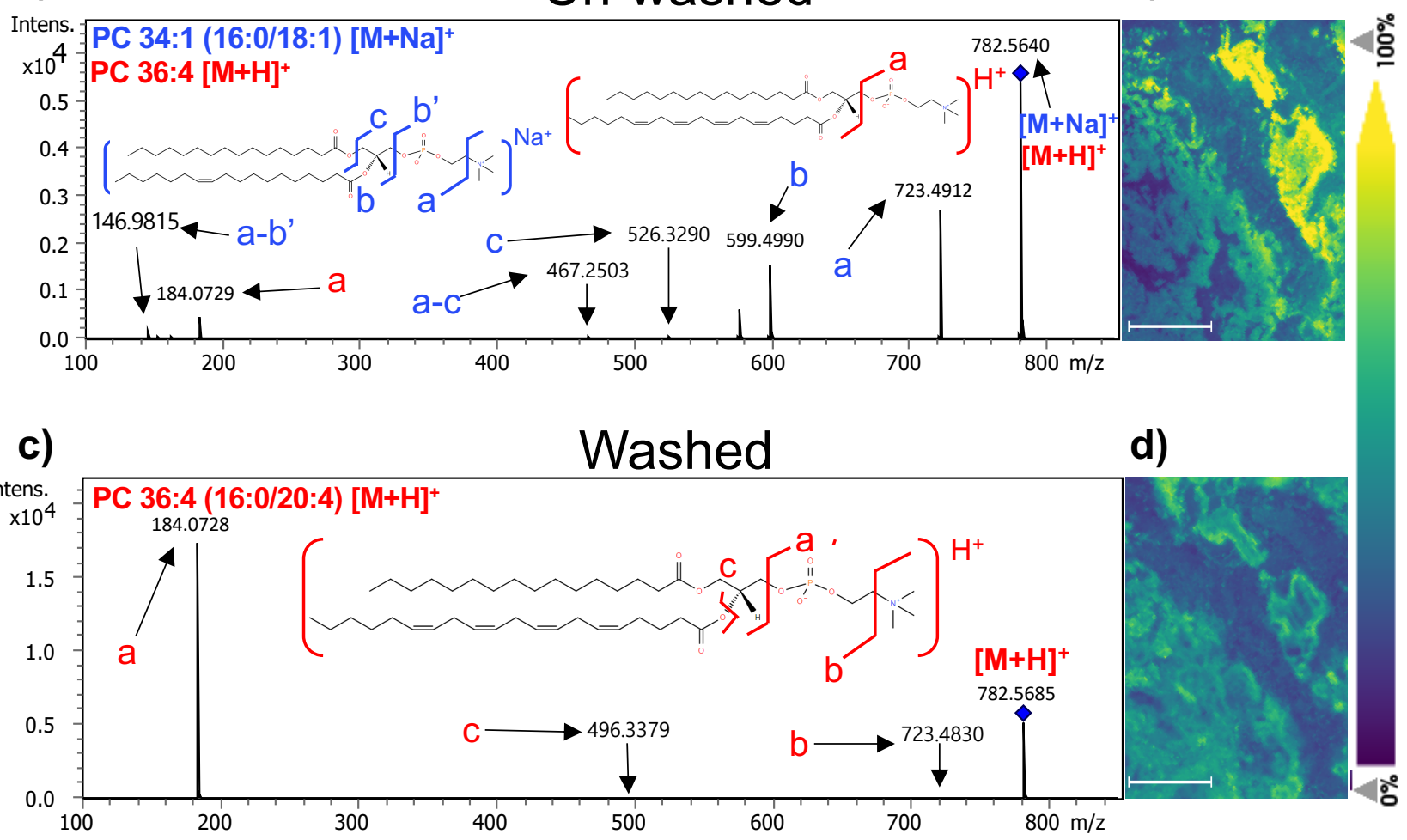

Figure 6. MS/MS spectra of precursor $m / z 782.5676$ containing isobaric PC species in a) unwashed and c) washed prostate xenograft tissue. MS/MS profiles acquired using CE $35 \mathrm{eV}$ and a precursor isolation width of $1.5 \mathrm{Da}$. Fragment ions and structural fragmentation pattern of PC 34:1 [M+Na $]^{+}$(blue) and PC 36:4 $[\mathrm{M}+\mathrm{H}]^{+}$(red) are displayed. $\mathrm{m} / z$ images depicting the change in spatial localization of $\mathrm{m} / \mathrm{z} 782.570$ between b) un-washed and d) ammonium formate washed prostate xenograft tissue sections. White scale bar represents $800 \mu \mathrm{m}$. Colour scale indicates signal intensity (a.u). Double bond position was not experimentally determined and is only for illustrative purposes. 